\title{
Users' verification of information system curriculum design model
}

\begin{abstract}
Usersô Involvement is very crucial in any model or system development in the domain of information systems. In a preliminary study conducted earlier, the findings shown that users faced difficulties during curriculum design process. Consequently, a model namely Information System Curriculum Design Model is proposed. The purpose of this paper is to perform usersôverification to ensure the proposed model meet requirements of users who are also called curriculum designers. Survey is conducted to gather responses from 90 curriculum designers in 20 Institution of Higher Learning (IHL). The survey findings indicate that each component of the proposed model is perceived important. Once the proposed model is verified, it is converted to a prototype for further testing in the future.
\end{abstract}

Keyword: Information systems; Curriculum design; Curriculum designers 